\title{
A REVIEW OF 156 ODONTOGENIC TUMOURS IN CALABAR, NIGERIA
}

\author{
C. E. ANYANECHI ${ }^{1}$ AND B. D. SAHEEB ${ }^{2}$ \\ ${ }^{1}$ Oral and Maxillofacial Unit, Department of Dental Surgery, University of Calabar Teaching Hospital, Cala- \\ bar, Nigeria, ${ }^{2}$ Department of Oral and Maxillofacial Surgery, University of Benin Teaching Hospital, Benin \\ City, Nigeria
}

DOI: http://dx.doi.org/10.4314/gmj.v48i3.9

Corresponding Author: Dr. Charles E. Anyanechi

E-mail:ceanyanechi@yahoo.com

Conflict of Interest: None declared

\section{SUMMARY}

Background: Odontogenic tumours occur in our environment and because of late treatment, cause considerable disabilities. Objective: To review cases of odontogenic tumours in our centre in order to obtain a baseline data and subsequently compare the results with that obtained elsewhere.

Patients and methods: Using hospital case files and register, we carried out a 15-year retrospective study of odontogenic tumours at the Dental and Maxillofacial Clinic, University of Calabar Teaching Hospital, Nigeria. The data documented include age, gender, duration of lesion, type of tumour, socio-economic class, type of surgery, and complaints during follow-up reviews.

Results: Majority of the patients $(n=49,31.4 \%)$ were in the third decade of life. There were $85(54.5 \%)$ males and $71(45.5 \%)$ females, giving male to female ratio of 1.2:1. There was a significant association between the type of odontogenic tumour and the age of occurrence $(p=0.000)$. The longer the duration of symptoms before presentation, the larger the tumours $(\mathrm{p}=0.000)$. The benign odontogenic tumours were 151 $(96.8 \%)$, ameloblastoma $(n=74,47.4 \%)$ being the commonest. Jaw resection $(54.5 \%)$ was the predominant treatment. Majority $(58.0 \%)$ of the complications following treatment were Facial deformity, malocclusion and impaired mastication.

Conclusion: Majority of the patients was in the lower socio-economic class, presented late for treatment and a few with aesthetic and functional impairment returned for secondary surgery. The intervention of agencies of government and non-governmental organizations is required to assist these patients if we are to accomplish the core healthcare system values in our environment.

Keywords: Odontogenic, tumour(s), ameloblastoma, late presentation, complications.

\section{INTRODUCTION}

Odontogenic tumours are derived from their cells of origin and their behaviour depend on whether they are benign or malignant. ${ }^{1}$ These tumours are of clinical significance because of their potential ability to jeopardize the health and longevity of the patient. They account for between 1.0 and $32.6 \%$ of oral lesions, and are mostly benign. ${ }^{1-4}$

Several studies ${ }^{5,6,7}$ have been carried out in Nigeria on the relative frequencies, incidences, clinical features, radiological appearances, histopathological characterization and treatment of these tumours in children and adults, but the report in the literature on the morbidity and complications caused by these relatively benign tumours is scanty. The purpose of this study is to obtain a baseline data for our centre and subsequently compare the results with that obtained elsewhere. Consequently, this paper reviews cases of odontogenic tumours in 156 patients who presented at the University of Calabar Teaching Hospital, Nigeria between 1996 and 2010 with emphases on duration of lesion, type of tumour, reasons for delay in treatment after diagnosis, and complaints during follow-up reviews.

\section{PATIENTS AND METHODS}

This is a retrospective study of odontogenic tumours in patients who presented at the Dental and Maxillofacial Clinic of the University of Calabar Teaching Hospital, Nigeria between January 1996 and December 2010. The types of odontogenic tumours were based on World Health Organisation (WHO) histopathological diagnosis criteria of 2005. Patients of both gender and of all ages with jaw swellings that were histopathologically diagnosed as odontogenic tumours were included in the study. 
The variables obtained from the patients' case files and hospital register were recorded in a proforma questionnaire. These include age, gender and duration of tumour; jawbone involved, size and type of the tumour. Other variables documented were socio-economic class, reasons for delay in treatment after diagnosis, type of surgery, and complaints during follow-up reviews. Subjects' socio-economic status was classified according to Adedeji's classification of $1985 .{ }^{8}$ The data obtained were statistically analysed using Statistical Package for Social Sciences (SPSS) version 13, Illinois, Chicago. $\mathrm{P}$ values $<0.05$ are considered significant.

\section{RESULTS}

Out of 167 subjects recorded, 156 (93.4\%) met the criteria for inclusion in the study. Table 1 shows the distribution of patients according to age and gender. No patient was recorded in the first decade of life, but the majority $(n=85,54.5 \%)$ were in the second and third decades. The age distribution ranged from 12-68 years with a mean of $33 \pm 2.3$ years. There were $85(54.5 \%)$ males and $71(45.5 \%)$ females, giving male to female ratio of 1.2:1.

Table 1 Distribution of patients according to age and gender

\begin{tabular}{|l|l|l|l|l|l|l|}
\hline $\begin{array}{l}\text { Age } \\
\text { Years }\end{array}$ & Female & & Male & & Total & \\
\hline & No. & $\%$ & No. & $\%$ & No. & $\%$ \\
\hline $11-20$ & 12 & 7.7 & 24 & 15.4 & 36 & 23.1 \\
\hline $21-30$ & 31 & 19.9 & 18 & 11.5 & 49 & 31.4 \\
\hline $31-40$ & 18 & 11.5 & 12 & 7.7 & 30 & 19.2 \\
\hline $41-50$ & 13 & 8.3 & 10 & 6.4 & 23 & 14.7 \\
\hline $51-60$ & 8 & 5.1 & 4 & 2.6 & 12 & 7.7 \\
\hline $61-70$ & 3 & 1.95 & 3 & 1.95 & 6 & 3.9 \\
\hline Total & $\mathbf{8 5}$ & $\mathbf{5 4 . 5}$ & $\mathbf{7 1}$ & $\mathbf{4 5 . 5}$ & $\mathbf{1 5 6}$ & $\mathbf{1 0 0 . 0}$ \\
\hline
\end{tabular}

Table 2 shows the age distribution of tumours. There was a significant association between the type of odontogenic tumour and the age of occurrence $\left(\chi^{2}=110.69\right.$, $\mathrm{df}=55, \mathrm{p}=0.000)$.

Table 2 Age distribution of odontogenic tumours

\begin{tabular}{|l|l|l|l|l|l|l|l|l|}
\hline $\begin{array}{l}\text { Tumour } \\
\text { Type }\end{array}$ & $\begin{array}{l}\mathbf{1 1 - 2 0} \\
\text { years }\end{array}$ & $\begin{array}{l}\mathbf{2 1 - 3 0} \\
\text { years }\end{array}$ & $\begin{array}{l}\mathbf{3 1 - 4 0} \\
\text { years }\end{array}$ & $\begin{array}{l}\mathbf{4 1 - 5 0} \\
\text { years }\end{array}$ & $\begin{array}{l}\mathbf{5 1 - 6 0} \\
\text { years }\end{array}$ & $\begin{array}{l}\mathbf{6 1 - 7 0} \\
\text { years }\end{array}$ & Total & Percentage \\
\hline Ameloblastoma & 2 & 20 & 37 & 7 & 6 & 2 & 74 & 47.4 \\
\hline Odontoma & 7 & 4 & 4 & 4 & 9 & 0 & 19 & 12.2 \\
\hline Odontognenic fibromyxoma & 2 & 4 & 4 & 2 & 0 & 0 & 12 & 7.7 \\
\hline Adenomatoid tumour & 7 & 4 & 0 & 0 & 0 & 0 & 11 & 7.1 \\
\hline Ameloblastic fibroma & 4 & 4 & 2 & 0 & 0 & 0 & 10 & 5.4 \\
\hline Cementoblastoma & 0 & 1 & 2 & 2 & 3 & 0 & 8 & 5.1 \\
\hline Odontogenic myxoma & 0 & 4 & 3 & 0 & 0 & 0 & 7 & 4.5 \\
\hline Ameloblastic fibrosarcoma & 0 & 2 & 1 & 1 & 1 & 0 & 5 & 3.2 \\
\hline Odontogenic fibroma & 0 & 4 & 0 & 0 & 0 & 0 & 4 & 2.6 \\
\hline Calcifying epithelial tumour & 0 & 1 & 2 & 0 & 0 & 0 & 3 & 1.9 \\
\hline Ameloblastic fibroodontoma & 0 & 0 & 2 & 0 & 0 & 0 & 2 & 1.3 \\
\hline Calcifying odontogenic cyst & 0 & 0 & 0 & 1 & 0 & 0 & 1 & 0.6 \\
\hline Total & $\mathbf{2 2}$ & $\mathbf{4 8}$ & $\mathbf{5 7}$ & $\mathbf{1 7}$ & $\mathbf{1 9}$ & $\mathbf{2}$ & $\mathbf{1 5 6}$ & $\mathbf{1 0 0}$ \\
\hline
\end{tabular}

$\mathrm{X}^{2}=110.69, \mathrm{df}=55, \mathrm{p}=0.000$

While ameloblastoma and odontoma were found to occur across a wide age range of up to sixth or seventh decade, others such as adenomatoid odontogenic tumour, odontogenic fibromyxoma, ameloblastic fibroma and odontogenic fibroma were found to occur predominantly within the second to fourth decades of life. The most common tumour was ameloblastoma $(n=74$, 47.4\%).The benign odontogenic tumours were 151 $(96.8 \%)$ while the malignant types were $5(3.2 \%)$. The mandibular tumours were $143(91.7 \%)$ while maxillary tumours accounted for 13(8.3\%). Similarly $38(24.4 \%)$ tumours affected one quadrant of the jaw while 118 $(75.6 \%)$ involved two quadrants.
Table 3 shows the distribution of tumour size according to time of presentation. There was a significant association between the size of tumour and duration of symptoms prior to presentation $\left(\chi^{2}=206.10, \mathrm{df}=12\right.$, $\mathrm{P}=0.000$ ). The longer the duration of symptoms before presentation, the larger the tumours. Majority of the patients $(=143,91.7 \%)$ presented between one and 12.5 years after they first noticed the lesion, while the duration of the tumour ranged from 9 months to 12.5 years. The number of patients increased with decreased socio-economic status as follows: class $1(n=6,3.9 \%)$, class $2(n=13,8.3 \%)$, class $3(n=37,23.7 \%)$, class 4 $(n=48,30.8 \%)$ and class $5(n=52,33.3 \%)$. 
Table 3 distribution of tumour size according to time of presentation

\begin{tabular}{|l|l|l|l|l|l|l|l|}
\hline $\begin{array}{l}\text { Tumour } \\
\text { size }(\mathbf{c m})\end{array}$ & $\begin{array}{l}<\mathbf{1} \\
\text { yrs. }\end{array}$ & $\begin{array}{l}\mathbf{1 - 3} \\
\text { yrs. }\end{array}$ & $\begin{array}{l}\mathbf{4 - 6} \\
\text { yrs. }\end{array}$ & $\begin{array}{l}\mathbf{7 - 9} \\
\text { yrs. }\end{array}$ & $\begin{array}{l}\mathbf{1 0 - 1 2} \\
\text { yrs. }\end{array}$ & Total & $\mathbf{\%}$ \\
\hline $1-3$ & 13 & 13 & 0 & 0 & 0 & 26 & 16.7 \\
\hline $4-6$ & 0 & 23 & 047 & 1 & 0 & 71 & 45.5 \\
\hline $7-9$ & 0 & 0 & 18 & 27 & 0 & 45 & 28.8 \\
\hline$>9$ & 0 & 0 & 0 & 4 & 10 & 14 & 9.0 \\
\hline Total & $\mathbf{1 3}$ & $\mathbf{3 6}$ & $\mathbf{6 5}$ & $\mathbf{3 2}$ & $\mathbf{1 0}$ & $\mathbf{1 5 6}$ & $\mathbf{1 0 0 . 0}$ \\
\hline
\end{tabular}

The duration in weeks between diagnosis of tumour and treatment is as follows: 1-4 $(n=46,29.5 \%), 5-8$ $(\mathrm{n}=51,32.7 \%), 9-12(\mathrm{n}=32,20.5 \%)$ and greater than 12 $(n=27,17.3 \%)$. Majority $(n=110,70.5 \%)$ were treated after 4 weeks of diagnosis, and these delays were due to financial constraints $(n=81,51.9 \%)$, unavailability of the theatre $(n=12,7.7 \%)$, phobia for surgery $(n=10$, $6.4 \%$ ), and "no relative to stay with me in the hospital" $(n=7,4.5 \%)$. The distribution of treatment show that $151(96.8 \%)$ received primary treatment while 3 $(1.9 \%)$ were inoperable and $2(1.3 \%)$ were referred to other centres in Nigeria. Jaw resection was done in $85(54.5 \%)$ cases while enucleation and curettage were performed in $66(42.3 \%)$.

The resections were segmental $(n=81,51.9 \%)$ and marginal $(n=4,2.6 \%)$. Following treatment, those that had discontinuity defect of the jaws were $127(81.4 \%)$ while those without it accounted for 24(15.9\%). Intermaxillary fixation (IMF) was done for those with discontinuity defect after one week of surgery, while partial dentures alone $(n=18,11.9 \%)$, and with obturator $(n=6,4.0 \%)$ were provided for patients without discontinuity defect after one year of surgery.

Table 4 Distributions of complications

\begin{tabular}{|l|l|l|}
\hline Complication & No. & \% \\
\hline Facial deformity & 134 & 19.7 \\
\hline Malocclusion & 131 & 19.3 \\
\hline Impaired mastication & 129 & 19.0 \\
\hline Numbness & 87 & 12.8 \\
\hline Limitation in mouth opening & 76 & 11.2 \\
\hline Altered speech & 73 & 10.8 \\
\hline Wound dehiscence & 21 & 3.1 \\
\hline Stitch abscess & 10 & 1.5 \\
\hline Oro-antral fistula & 7 & 1.0 \\
\hline Recurrence & 5 & 0.7 \\
\hline Respiratory distress & 4 & 0.6 \\
\hline Drooling of saliva & 2 & 0.3 \\
\hline Total & $\mathbf{6 7 9}$ & $\mathbf{1 0 0 . 0}$ \\
\hline
\end{tabular}

Although most of the subjects kept irregular appointments, the duration of follow-up ranged from 3.5 months to 10.2 years with a mean of 4.3 years. The complications recorded following treatment are shown in Table 4. Facial deformity, malocclusion and impaired mastication accounted for $58.0 \%$. Those who wanted secondary surgery $(n=11,7.1 \%)$ out of $127(81.4 \%)$ that needed it, were referred to other centres in Nigeria. The other complications including recurrences due to ameloblastoma, fibromyxoma and myxoma $(n=5,3.3 \%)$ were managed in our centre.

\section{DISCUSSION}

Odontogenic tumours contribute to the neoplastic disease profile in the head and neck region. ${ }^{5,7}$ However, when considered globally, there is considerable racial predilection for the specific tumour types. ${ }^{2,3,4}$ This study shows that benign tumours $(96.8 \%)$, particularly ameloblastoma $(47.4 \%)$ were the most common. This confirms the report of several studies ${ }^{9-11}$ but differs from those of Luo and Li, ${ }^{12}$ and Ebenezer and Ramalinqam, ${ }^{13}$ on the individual tumours that are more common, as they recorded predominantly keratocystic odontogenic tumour (38.7\%) and odontoma (56\%) respectively in their study.

There was a significant association between the type of odontogenic tumour and the age of occurrence in this study. The peak and mean (33 years) ages obtained are similar to previous studies ${ }^{6,11,14}$ but differ from the study $^{15}$ in Egypt where 29.6 years was recorded as mean age. Furthermore, it has been documented in the literature $^{16}$ and confirmed in this study that odontogenic tumours may not manifest in the first decade of life. Although, it may not be detected in early childhood, their prevalence increases with age. ${ }^{9,16}$ There was an almost equal gender distribution in the occurrence of these tumours in both sexes in the present study (M: $\mathrm{F}=1.2: 1$ ) which is similar to previous reports ${ }^{11,15,16}$, but contrast to the female preponderance recorded by $\mathrm{Wu}$ and Chan in their study. ${ }^{4}$

The mandibular tumours $(91.7 \%)$ were more than the maxillary tumours. This is similar to earlier reports 5,14 but differs from those of Arotiba et al. ${ }^{6}$ who documented equal distribution between both jaws. Likewise, $75.6 \%$ of the tumours involved two quadrants, which could be attributed to delay in presentation. In this study, the duration of the symptoms of the tumours ranged from 9 months to 12.5 years, and the longer the duration before presentation, the larger the tumours. 
This duration is higher than those of earlier authors $^{5,6,9,14}$ from Nigeria but confirmed their assertion that patients afflicted with these diseases in our environment do not present early at the appropriate centers for treatment.

This delay in treatment even after diagnosis accounted for the large sizes of the tumours and requires prompt intervention by the relevant government and nongovernmental agencies, since majority $(n=100,64.1 \%)$ are in the lower socio-economic class. These should be done if we are to accomplish the core healthcare system values in our environment which include universal access to all citizens, effective care for better health outcomes, efficient use of resources, high-quality services and responsiveness to patient concerns.

The $1.9 \%$ cases that were inoperable were due to late presentation resulting from spread to the base of the skull, and infratemporal fossa which led to gross limitation of mouth opening. Such cases have been reported by earlier authors. ${ }^{7,14}$ The $1.3 \%$ cases referred to other centres in Nigeria were those that needed composite resection. The surgical procedures used for treatment have been reported by previous researchers. ${ }^{17,18 \text {, }}$ ${ }^{19}$ The finding in this study confirmed their assertion that resection of the tumour with adequate margin of normal bone was adequate for locally invasive tumours like ameloblastoma, odontogenic fibromyxoma and myxoma, whereas the use of enucleation and curettage led to recurrence of these lesions.

As noted by Arotiba et al $^{6}$, the rate of recurrence $(n=5$, $3.3 \%$ ) in this study may be underestimated as the follow-up period was short and recurrences have occurred 30 years after operation. Life time follow-up is advocated for ameloblastoma, myxoma and fibromyxoma. Also, intermaxillary fixation was done to prevent collapse of jaw fragments in those with discontinuity defects while partial denture with or without obturator was provided to enhance aesthetics and functional adaptation of the patients.

Although disease eradication may be the most important objective of treatment, it is sometimes inadequate in the overall treatment of the patients. The other goal of treatment is to carry out functional and aesthetic rehabilitation because of complications following surgery. The complications recorded in the present study have been documented by earlier authors. 7, 10, 20 Although, these complications have been reported by previous authors, facial deformity, malocclusion and impaired mastication were not predominant as in the present study.
These conditions were due to large sizes of the tumours resulting from late presentation and the consequent wide surgical procedures carried out to eradicate the disease process. These wide surgical procedures would have been largely avoided if the tumours were smaller in sizes. Also because of delay in treatment, $81.4 \%$ of the subjects had discontinuity defect following surgery which ultimately contributed to most of the complications recorded. As patients who present with these defects have aesthetics and functional impairment, secondary surgery is required to improve their quality of life and wellbeing. Due to financial constraints only $7.1 \%$ opted for it in this study, and the others $(74.3 \%)$ decided to come to terms with their deformities.

\section{CONCLUSION}

Odontogenic tumours, particularly ameloblastoma do occur in our environment. The predominant treatment method was jaw resection and following treatment, facial deformity, malocclusion and impaired mastication were the most common complications recorded. Majority of the patients was in the lower socioeconomic class, presented late for treatment and a few of those with aesthetic and functional impairment returned for secondary surgery. The intervention of agencies of government and non-governmental organizations is required to assist these patients if we are to accomplish the core healthcare system values in our environment.

\section{ACKNOWLEDGEMENT}

We wish to express our sincere gratitude to Mrs Adiaha Ofem of the Department of Records and Information Management, University of Calabar Teaching Hospital, Calabar for her assistance in sorting out the case files of the subjects.

\section{REFERENCES}

1. Malik NA. Textbook of oral and maxillofacial surgery. New Delhi: Jaypee, 2008: 469-496.

2. Ulmansky M, Lustmann J, Balkin N. Tumours and tumour-like lesions of the oral cavity and related structures in Israeli children. Int J Oral Maxillofac Surg1999; 28: 291-294.

3. Gunhan O, Erseven G, Ruacan S. Odontogenic tumours, a series of 409 cases. Aut Dent J 1990; 35: 518-522.

4. Wu PC, Chan KW. A survey of tumours of the jaw bone in Hong Kong Chinese 1963-1982. Br J Oral Maxillofac Surg 1985; 23: 92-102.

5. Odukoya O. Odontogenic tumours: analysis of 289 Nigerian cases. J Oral Pathol Med 1995; 24: 454457. 
6. Arotiba JT, Ogunbiyi JO, Obiechina AE. Odontogenic tumours: a 15-year review from Ibadan, Nigeria. Br J Oral Maxillofac Surg 1997; 35: 363367.

7. Adebayo ET, Ajike SO, Adekeye EO. Odontogenic tumours in children and adolescents: a study 78 Nigerian cases. J Cranio Maxillofac Surg 2002; 30: 267-272.

8. Adedeji GA. Socio-economic and cultural background of hospitalized children in Ilesha, Nigeria. Nig J Paed 1985; 12: 111-117.

9. Adebayo ET, Ajike SO, Adekeye EO. A review of 318 odontogenic tumours in Kaduna, Nigeria. $J$ Oral Maxillofac Surg 2005; 63: 811-889.

10. Fernandes AM, Duarte EC, Pimenta FJ, Souza LN, Santos VR, Mesquita RA, de Aquiar MC. Odontogenic tumours: a study of 340 cases in a Brazilian population. J Oral Pathol Med 2005; 34: 583-587.

11. Jing W, Xuan M, Lin Y, Wu L, Liu L, Zheng X, Tang W, Qiao J, Tian W. Odontogenic tumours: a retrospective study of 1642 cases in a Chinese population. Int J Oral Maxilofac surg 2007; 36: 20-25.

12. Luo HY, Li TJ. Odontogenic tumours: a study of 1309 cases in a Chinese population. Oral Oncol 2009; 45: 706-711.

13. Ebenezer V, Ramalinqam B. A cross-sectional survey of prevalence of odontogenic tumours. $J$ maxillofac Oral Surg 2010; 9: 369-374.
14. Akinmoladun VI, Udeabor SE, Arotiba GT. Pattern of odontogenic tumours in Nigeria: a review of literature. Nig Dent J 2010; 18: 212-216.

15. Tawfik MA, Zyada MM. Odontogenic tumours in Dakahlia Egypt: analysis of 82 cases. Oral Surg Oral Med Oral Pathol Oral Radiol Endod 2010; 109: e67-73.

16. Servator JP, de Souza PE, Horta MC, Ribeiro DC, de Aquiar MC, de Faria PR, Cardoso SV, Loyola AM. Odontogenic tumours in children and adolescent: a collaborative study of 431 cases. Int J Oral Maxillofac Surg 2012; 41: 768-773.

17. Tamme T, Soots M, Kulla A, Karu K, Hanstein SM, Sokk A, Joeste E, Leibur E. Odontogenic tumours, a collaborative retrospective study of 75 cases covering more than 75 years from Estonia. $J$ Craniomaxillofac Surg 2004; 32: 161-165.

18. Lu Y, Xuan M, Takata T, Wang C, He Z, Zhou Z, Mock D, Nikai H. Odontogenic tumour. A demographic study of 759 cases in a Chinese population. Oral Med Oral Surg Oral Pathol Radiol Endod 1998; 86: 707-714.

19. Ochsenius G, Ortega A, Godoy L, Penafiel C, Escobar E. Odontogenic tumours in Chile: a study of 362 cases. J Oral Pathol Med 2002; 31: 415-420.

20. Adekeye EO, Apapa DJ. Complications and morbidity following surgical ablations of the jaws. West Afr J Med 1987; 193-200. 